\title{
LA DESVIACIÓN DE J. S. MILL: EL PUESTO DE LAS EMOCIONES EN EL UTILITARISMO ${ }^{1}$
}

\author{
ÍÑIGO Álvarez GÁLVEZ \\ Universidad de Chile
}

\begin{abstract}
RESUMEN
Se afirma a menudo que el utilitarismo (al menos su versión estándar) es incapaz de tomar en cuenta las emociones. Siendo esto así, se afirma que es incapaz de responder (correctamente) a nuestros problemas morales más importantes y que, de hecho, se convierte en una doctrina inútil. Sin embargo, debemos matizar esta acusación diciendo, por un lado, que las emociones tienen, de algún modo, un significativo papel en la teoría de Bentham y que, por otro lado, tienen, indudablemente, un papel central en el utilitarismo de Mill. En este artículo tratamos de mostrar cuál es ese papel y si el uso de las emociones en la teoría de Mill puede ser visto como una especie de desviacionismo de la versión estándar.
\end{abstract}

Palabras claves: Emociones; utilitarismo; cálculo; felicidad.

\begin{abstract}
It is often said that utilitarianism (at least the standard version) is incapable of taking emotions into account. That being so, it is also said that it is incapable of answering (properly) to our most important moral problems, and, in fact, it becomes a useless doctrine. However, we must qualify this accusation by saying, on the one hand, that emotions play, in some way, a significant role in Bentham's theory, and on the other hand, that they undoubtedly play a central role in Mill's utilitarianism. In this article we try to establish what that role is and whether the use of emotions in Mill's theory could be seen as a kind of departure from the standard version.
\end{abstract}

Keywords: Emotions; Utilitarianism; Calculus; Happiness.

La cuestión que nos planteamos en el presente trabajo es la del lugar que ocupan los sentimientos en el utilitarismo en general y en el utilitarismo

1 Recepción: 31 de agosto de 2010. Aceptación: 20 de diciembre de 2010.

TÉ $\lambda \circ$ 与, Vol. XVII/2, 2010 (145-170) 
de Mill en particular; y, enlazado con esto, la cuestión sobre lo que supone conceder un espacio a los sentimientos en la doctrina utilitarista, como hace Mill, y hasta qué punto eso puede concebirse como una especie de desviacionismo. ${ }^{2}$

\section{LA AUSENCIA DE LOS SENTIMIENTOS EN EL UTILITARISMO}

Una de las acusaciones que de forma recurrente se han dirigido contra el utilitarismo (llamémosle estándar) es la de que se trata de una doctrina en la que no caben los sentimientos, de modo tal que la propuesta moral queda muy lejos de nuestras intuiciones morales más comunes y, en definitiva, es poco menos que inútil. ${ }^{3}$

En todo caso, esta acusación necesita ser precisada, pues de ninguna manera se puede decir que los sentimientos no aparezcan ni por asomo en la doctrina utilitarista. Tomemos como referencia la propuesta de Bentham (que bien puede ser presentada como doctrina estándar):

Es obvio que en la doctrina de Bentham las emociones ocupan un lugar importante. Para empezar, toda su propuesta se sustenta sobre las ideas del dolor y el placer, cuya vinculación con las emociones es evidente. En Una introducción a los principios de la moral y la legislación, Bentham

2 Advierto desde el comienzo que no seré preciso en la utilización de los términos "emoción" y "sentimiento". No es el asunto que nos ocupa en este momento y, por lo que nos interesa, emplearé de manera indistinta uno y otro. Hay autores, como Damásio por ejemplo, que distinguen entre "emoción" y "sentimiento", pero otros muchos los emplean como sinónimos o incluso, como hace Ferrater (Diccionario de filosofía, 5 vols., Barcelona, RBA, 2005, v. 5, pg. 3241), proponen, visto el grado de ambigüedad, eliminar el término "sentimiento" en favor del término "emoción". En efecto, afirma Damásio $(O$ erro de Descartes. Emoção, razão e cérebro humano, Mem Martins, Publicações EuropaAmérica, 2005, pg. 153): "La emoción es la combinación de un proceso evaluador mental, simple o complejo, con respuestas dispositivas a ese proceso, en su mayoría dirigidas al cuerpo propiamente dicho, dando por resultado un estado emocional del cuerpo, pero también dirigidas al propio cerebro (núcleos neurotransmisores en el tronco cerebral), dando por resultado alteraciones mentales adicionales. Nótese que, de momento, dejo fuera de la emoción la percepción de todos los cambios que constituyen la respuesta emocional. Como se verá en breve, reservo el término sentimiento para la experiencia de esos cambios”. Y más adelante dirá: “¿Qué me lleva a no usar indistintamente los términos 'emoción' y 'sentimiento'? Una de las razones se encuentra en el hecho de que a pesar de que algunos sentimientos estén relacionados con las emociones, existen muchos que no lo están: todas las emociones originan sentimientos, si se está despierto y atento, pero no todos los sentimientos provienen de emociones" (Damásio, o.c., pg. 157). Otros autores, en cambio, emplean los términos 'emoción' y 'sentimiento' como sinónimos (quizás la mayoría en el ámbito científico, pues el propio Damásio (ob.cit., pg. 159) reconoce que sus definiciones no son ortodoxas y que otros colegas suyos usan tales palabras de manera indiferenciada).

3 No se trata ahora de dilucidar si se puede hablar del utilitarismo (en singular) o si es más apropiado decir los utilitarismos (en plural) y especificar a cuál de ellos se dirige la mencionada crítica. Creo que es tan común decir que existen muchos tipos de utilitarismo como referirse a la doctrina como si sólo existiera uno. 
comienza precisamente con la referencia a estas ideas. ${ }^{4} \mathrm{Y}$ lo que desarrolla después no es sino un estudio pormenorizado de los distintos tipos de placeres y dolores, de las acciones, de la intención, de la conciencia, de los motivos o de las disposiciones. Todo esto, por supuesto, tiene una clara finalidad política (decirle al legislador cuáles son sus herramientas y cómo debe manejarlas para dirigir a los individuos a la consecución de la mayor felicidad para el mayor número); pero su obra es también, sin duda, una obra de psicología, o como él mismo la denomina, una obra de fisiología moral. Lo que pretende Bentham es hacer un estudio científico de las funciones de los seres orgánicos en relación con la moral; pretende un estudio científico del comportamiento humano, en el que, como no podía ser de otro modo, ocupan un lugar central las emociones. Así pues, no cabe decir sin más que las emociones no aparezcan en la propuesta utilitarista.

Donde se puede decir que no aparecen es en el tipo de cálculo moral que el utilitarismo propugna. Bentham, decíamos, pretendía hacer un estudio científico del comportamiento humano y de la moral; pretendía dar un tratamiento científico a las cuestiones morales, de manera tal que los resultados pudieran ser comparables, por ejemplo, a los de las matemáticas. Desde su punto de vista, "las verdades que forman la base de las ciencias política y moral no podrán ser descubiertas sino mediante investigaciones tan rigurosas como son las investigaciones matemáticas [...] No florecen en el mismo suelo que el sentimiento. Crecen entre las espinas; y no pueden ser recogidas como si fueran margaritas por niños que corretean". ${ }^{5}$ Así pues, el estudio del bien y del mal que Bentham propone es un estudio científico en el que no hay espacio para el sentimiento. No es tanto que los sentimientos no puedan ser objeto de estudio, sino que el estudio de que pueden ser objeto es no valorativo y emocionalmente neutro. El científico moral, en suma, en tanto científico, adopta un punto de vista alejado de toda emoción.

4 "La naturaleza — asegura - ha situado a la humanidad bajo el gobierno de dos amos soberanos, el dolor y el placer. Es sólo por ellos por los que determinamos lo que debemos hacer, así como determinamos lo que haremos. Por un lado, el criterio de lo correcto y lo incorrecto; por otro, la cadena de causas y efectos está atada a su trono. Nos gobiernan en todo lo que hacemos, en todo lo que decimos, en todo lo que pensamos. Cualquier esfuerzo que hagamos para desprendernos de nuestra sujeción sólo servirá para demostrarla y confirmarla. De palabra un hombre puede pretender abjurar de su imperio; pero en la realidad, seguirá sujeto a él de cualquier modo. El principio de utilidad reconoce esta sujeción y la asume para la fundación de este sistema, cuyo objeto es levantar el armazón de la felicidad mediante la razón y la ley" (Bentham, Jeremy, A Fragment on Government and An Introduction to the Principles of Morals and Legislation, Oxford, Basil Blackwell, 1960, pg. 125).

5 Bentham, Jeremy: Escritos económicos, México, Fondo de Cultura Económica, 1965, pg. 124. 
Y así lo hizo Bentham al defender la idea de que la bondad o maldad de las acciones dependía de la felicidad que pudieran producir. "La mayor felicidad del mayor número" es la expresión de un fin objetivo y mensurable. La felicidad producida por cualquier comportamiento humano, (entendida siempre como el placer y la ausencia de dolor) podía ser calculada tomando en consideración elementos tales como la intensidad del placer o dolor producido, su duración, su certeza, su cercanía, su fecundidad, su pureza y su extensión. Y en ese cálculo es imprescindible que no aparezca ningún asomo de sentimiento so pena de contaminar, y en definitiva arruinar, la conclusión. Si se quiere llegar a un resultado objetivo, el científico moral debe ser escrupulosamente neutro y evitar toda influencia de sus emociones. Las únicas emociones involucradas en su trabajo son aquéllas que son tratadas como datos para el cálculo de la felicidad.

Bentham presenta un método de medición completo y complejo. De acuerdo con lo que él propone, el científico moral (o el legislador) debe considerar en cada acción humana todos los placeres y dolores que la tal acción produce a cada uno de los sujetos a los que afecta, tomando en consideración los siete elementos mencionados. Elaborado ese cálculo (matemático, a fin de cuentas), es decir, sumados todos los placeres y restados todos los dolores provocados por la acción, se puede concluir afirmando el monto de felicidad o infelicidad que acompaña a la acción y, por tanto, su valoración moral. Esta exactitud, precisión y objetividad pretendida requiere, como decíamos, el abandono de cualquier sentimiento o emoción en la realización del cálculo.

Bien es cierto que la postura de Bentham en relación con este cálculo es titubeante. Por momentos defiende la posibilidad y la necesidad de hacer una medición precisa e incluso propone que se tome el dinero como medida $;^{6}$ en otros lugares, en cambio, considera que se debe tener en cuenta apenas como una meta hacia la que tender y no como una exigencia rigurosa. ${ }^{7}$ Pero en todo caso, sea lo que sea de esto, ciertamente el cálculo objetivo de la felicidad producida por los comportamientos le parecía posible (y

6 "Ya hemos señalado - afirma en "La psicología del hombre económico" - que el dinero (esto es, la proporción entre una determinada suma de dinero y la suma total del capital de un individuo) es la medida más exacta de la cantidad de dolor o de placer que cualquier hombre pueda recibir" (Bentham, J., Escritos económicos, cit., pg. 17). Y más abajo continúa: "De su dinero es de donde procede la parte principal de los placeres del hombre, y es la única que es susceptible de cálculo" (Bentham, ibídem).

$7 \quad$ "No es de esperar — sostiene- que este procedimiento deba ser seguido estrictamente antes de cada juicio moral o de cada acto legislativo o judicial. Sin embargo, debe ser tenido en cuenta siempre; y cuanto más cerca de él esté el procedimiento que se lleve a cabo, más se acercará a un procedimiento exacto" (Bentham, J., A Fragment on Government and..., cit., pg. 153). 
deseable si se pretendía alcanzar un grado científico razonable). Esa es la razón, por ejemplo, de que rechace como criterios morales no sólo el principio del ascetismo (opuesto al de la utilidad), sino también el principio de la simpatía (que en ocasiones, por cierto, coincide con el de la utilidad). ${ }^{8} \mathrm{Y}$ esa es la razón también que está detrás de su esfuerzo por depurar el lenguaje de términos emotivos, que contaminan y arruinan cualquier análisis que quiera ser científico; es decir, objetivo, riguroso y, en definitiva, contrastable con la realidad y, en consecuencia, digno de ser creído.

De acuerdo con esto, el buen utilitarista es aquel individuo que es capaz de valorar moralmente los comportamientos humanos (propios o ajenos) de acuerdo con un cálculo de los placeres y dolores producidos para decidir, en función de ello, qué acción debe hacerse y cuál evitarse; ${ }^{9}$ pero sobre todo, que es capaz de hacerlo dejando a un lado sus sentimientos. Dicho sea de paso, esta imagen del buen utilitarista como un individuo calculador, frío e insensible no podía ser ni beneficiosa para la difusión de la doctrina ni agradable para sus defensores. Todavía en el ámbito de la ciencia cabe pensar que el buen científico debe dejar a un lado sus sentimientos si quiere ser riguroso y objetivo (aunque no estoy seguro de hasta qué punto pueda ser una alabanza afirmar de un científico que es frío e insensible). Lo que, en cambio, no parece que pueda tener la misma aceptación generalizada es que en el ámbito moral también sea valioso ese rechazo de los sentimientos.

Bien mirado, tal vez pudiera defenderse, como así hizo Bentham, que dicho rechazo era necesario para dotar al análisis moral de un rigor científico imprescindible y de una objetividad indiscutible. Nadie podría levantar ninguna acusación seria contra una doctrina que, agrade o repugne,

8 La razón del rechazo de este principio de la simpatía y la antipatía es que, de acuerdo con él, la valoración de una acción depende simplemente de la aprobación o desaprobación del que la juzga (Bentham, J., A Fragment on Government and..., cit., pg. 139); en definitiva, de su sentimiento de aprobación o desaprobación. "Lo que uno espera encontrar en un principio - asegura - es algo que indique alguna consideración externa, como medio de garantizar y guiar los sentimientos internos de aprobación y desaprobación. Esta esperanza no se puede cumplir con una proposición que no hace ni más ni menos que sostener que cada sentimiento es una razón y un criterio por sí mismo" (Bentham, J., A Fragment on Government and..., cit., pg. 140). "Todo aquello que uno interiormente se incline a condenar — dice después_- es malo por esa misma razón" (Bentham, ibidem).

9 Como afirma, por ejemplo, Moore en su Ética al presentar la doctrina utilitarista, "si un ser cualquiera en cualquier circunstancia, tuviera que escoger entre dos acciones, una de las cuales produjera más placer que la otra, el deber del individuo en cuestión sería siempre escoger la primera más bien que la segunda; y que esto es una verdad absolutamente incondicionada" (Moore, George Edward: Ética, Barcelona, Labor, 1989, pg. 24). 
sea atractiva o aborrecible, llega a conclusiones verdaderas. Lamentablemente, el ámbito de la moral no es el ámbito de la ciencia, y, en consecuencia, se hace difícil esgrimir la verdad como el punto fuerte de cualquier doctrina moral. ${ }^{10}$

Y puestas así las cosas, la imagen del utilitarismo se deteriora aún más, porque ya no es sólo que el buen utilitarista sea un individuo insensible, preocupado exclusivamente de hacer un cálculo preciso; es que además esa insensibilidad que dirige el cálculo se trasmite también a la aceptación de las consecuencias de la aplicación de dicho cálculo. El buen utilitarista, se dice, tendrá que asentir impávido a consecuencias abominables derivadas de su cálculo. Su insensibilidad no sólo es disparatada respecto del cálculo de la felicidad; resulta que también esa forma de conducirse lo obliga a aceptar, a dar por buenas en nombre de la neutralidad valorativa y la asepsia sentimental, consecuencias inaceptables. Por ejemplo, el buen utilitarista, se dice, tendrá que aceptar una sociedad de seres abúlicos pero satisfechos (o utilizando las palabras que se han empleado a veces, una sociedad de cerdos satisfechos) si es así como se consigue la mayor felicidad del mayor número. $\mathrm{O}$ tendrá que aceptar que se pueda pasar por encima de la integridad de las personas (incluida la suya propia). ${ }^{11} \mathrm{O}$, en fin, tendrá

10 En relación con el utilitarismo se ha dicho, por ejemplo, que la supuesta verdad que pretende alcanzar esta doctrina es una quimera. En unos casos, se afirma, porque el cálculo de las consecuencias es imposible. Como apuntaba Alfred Ayer (Ensayos filosóficos, Barcelona, Planeta-Agostini, 1986, pg. 242), por ejemplo, parece que lo que nos quieren decir los utilitaristas al proponer el cálculo felicífico es que antes de asesinar a César, Bruto tenía que haber tenido en cuenta, entre otras cosas, la posible existencia de un Shakespeare escribiendo Julio César y la repercusión que esto tendría en la felicidad general, lo cual es obviamente un absurdo. En otros casos, porque las valoraciones de las personas no son comparables y, por tanto, de nuevo, el cálculo es un absurdo. También en palabras de Ayer: "¿En virtud de qué norma de medida puedo yo empezar a sumar la satisfacción de una persona a la de otra y a restar la cantidad que resulte del descontento de otro? Es evidente que tal norma no existe, y el proceso que Bentham propone de un 'cálculo sereno' resulta que es un mito" (Ayer, ibídem). Mackie se refiere a lo mismo cuando afirma respecto de los utilitaristas: "Hablan a menudo como si existiese alguna entidad, la felicidad, que fuera homogénea en ciertos sentidos y susceptible, en principio, de ser medida, actúan como si las diferentes partes o constituyentes de la felicidad pudiesen reducirse de algún modo a una única escala y ser sopesados objetiva y decisivamente unos con otros [...] El cálculo utilitarista es un mito y, según creo, no es un mito útil" (Mackie, J. L.: Ética. La invención de lo bueno y lo malo, Barcelona, Gedisa, 2000, pg. 157). Y Dworkin es igualmente claro: "En todo caso — asegura-, sería imposible identificar, medir y sumar los diferentes placeres y dolores que experimenta una gran cantidad de personas" (Dworkin, Ronald, Los derechos en serio, Barcelona, Ariel, 1977, pg. 340).

11 Bernard Williams, por ejemplo, sugiere dos situaciones en las que esto ocurriría. En una de ellas, un químico, contrario a las armas biológicas, debe decidir si aceptar o no un trabajo en una empresa dedicada precisamente a eso, sabiendo que si no lo acepta, el puesto será ocupado por un partidario de tales armas; en la otra, un turista debe decidir si matar o no a uno de los varios insurgentes detenidos en el país que visita, pues ésa 
que asumir su incapacidad para proteger los derechos de las personas y para respetar a las personas como fines en sí mismos. ${ }^{12}$

En conclusión, lo que se afirma es que el utilitarismo (o el utilitarismo benthamita) fomenta el desarrollo de seres fríos e insensibles; de perfectos calculadores que en el terreno moral son incapaces de tener empatía con sus semejantes y, por tanto, se ven abocados a aceptar y a querer (aunque no los deseen), resultados que pasan por encima de los derechos de las personas, desconocen su integridad o toman a los individuos como medios. Si esto es así, entonces la doctrina es rechazable. Y si esto es así a causa de ese rechazo de los sentimientos, entonces puede decirse que el utilitarismo debe ser repudiado, entre otros motivos, precisamente por su incapacidad

es la condición que ha puesto el capitán del ejército para perdonar la vida a los demás. Según Williams, el químico debería aceptar el puesto y el turista debería matar al detenido, puesto que esos son los comportamientos que causan el mayor bien para el mayor número. Esto supone, dice Williams, que el utilitarismo es incapaz de comprender la integridad de las personas; que "no puede describir de manera coherente las relaciones entre los proyectos de un hombre y sus acciones" (Smart, J.J.C. y Williams, Bernard, Utilitarianism: For and Against, Cambridge, Cambridge University Press, 1988, pg. 100). En un sentido similar, Raphael plantea el caso de alguien que tiene que decidir a quien salvar en un incendio, bien a un gran benefactor de la sociedad o bien a su propia madre. Un buen utilitarista deberá decidirse por el benefactor de la sociedad, pues es lo que produciría la mayor felicidad para el mayor número; de modo que, dice Raphael, el utilitarismo no puede percibir que "los vínculos personales cuentan más que los elementos de la utilidad social" (Raphael, David Daichies, Filosofía moral, México, Fondo de Cultura Económica, 1986, pg. 120).

12 Así lo dice, por ejemplo, Rawls, cuando afirma que "el principio de utilidad exige probablemente que algunos de los menos favorecidos acepten incluso menores perspectivas de vida a favor de otros" (Rawls, John, Teoría de la justicia, Fondo de Cultura Económica, Madrid, 1995, pg. 210), poniendo de manifiesto que el utilitarismo (clásico) "no puede tomar en serio la distinción entre personas" (Rawls, J., Teoría de la justicia, cit., pg. 218) y utiliza a unas como medio para conseguir la mayor felicidad de otras. Así lo dice también Nozick cuando sugiere que el utilitarismo permite la violación de los derechos si así se aumenta la felicidad general. Incluso en un utilitarismo en el que se pretendiera evitar las violaciones de los derechos, dice Nozick, "esto aún requeriría de nosotros que violáramos los derechos de algunos cuando, al hacerlo así, minimizáramos la cantidad total (sopesada) de la violación de derechos en la sociedad" (Nozick, Robert, Anarquía, Estado y utopía, Buenos Aires, Fondo de Cultura Económica, 1991, pg. 41). Así lo afirma Dworkin, cuando asegura que si no se entienden los derechos como triunfos políticos y, como parece que hace el utilitarismo, se incluyen en los debates sobre las metas colectivas, las preferencias externas de una mayoría pasarán por encima de ellos. Para Dworkin, el utilitarismo es incapaz de entender que "si alguien tiene un derecho a algo, está mal que el gobierno se lo niegue, aunque negárselo favoreciera el interés general" (Dworkin, Ronald, Los derechos en serio, cit., pg. 384). Y, en fin, así lo sostiene Nino cuando defiende que "el papel de los derechos en cuestión consiste en 'atrincherar' determinados intereses de los individuos, de modo que ellos no puedan ser dejados de lado, contra su voluntad, en atención a intereses que se juzgan más importantes — sea intrínsecamente o por el número de sus titulares - de otros individuos" (Nino, Carlos Santiago, Ética y derechos humanos, Barcelona, Ariel, 1989, pg. 261), que es precisamente lo que permite el utilitarismo. 
para darles cabida. Y en consecuencia, si se desea otorgar un puesto importante a los sentimientos en el ámbito moral, debe abandonarse la doctrina utilitarista.

¿Es posible ser un buen utilitarista y conceder un papel importante a los sentimientos? Creo que J. S. Mill lo hizo y que su desviación del benthamismo consiste, entre otras cosas, en otorgar a los sentimientos una función principal (lo que, por cierto, tiene consecuencias decisivas para atajar muchas de las acusaciones que se han dirigido a la doctrina).

\section{El desviacionismo de J. S. Mill}

No deja de ser llamativo el hecho de que alguna de estas críticas mencionadas más arriba haya sido formulada precisamente por un utilitarista como J. S. Mill. Para algunos intérpretes, las observaciones que hace Mill, expresamente al enfoque de Bentham, pero también, de manera menos expresa, al de su padre James Mill, hacen de él un tipo extraño de utilitarista, un utilitarista desviacionista o, sin más, un falso utilitarista.

John Mill reconoce, sin duda, los méritos de su padre y de Bentham. Las páginas que le dedica a su padre en su autobiografía dan buena muestra de la importancia intelectual de su progenitor y de la influencia decisiva que tuvo en él. John Stuart reconoce su valor intelectual, su fuerza espiritual y su valentía moral, y alaba el esfuerzo que dedicó a la educación de sus hijos. ${ }^{13} \mathrm{Y}$ en Bentham vio al maestro y a su guía moral. ${ }^{14}$ Pero con

13 Valga sólo como ejemplo: Alaba en la Autobiografía "la extraordinaria energía que fue requerida para llevar el tipo de vida que él llevó [...] manteniendo, como fue su caso, opiniones en materia de política y de religión que resultaban odiosas [...] a todas las personas influyentes y la gran mayoría de los ciudadanos ingleses que disfrutaban de una cierta prosperidad" (Mill, John Stuart, Autobiografía, Madrid, Alianza Editorial, 1986, pg. 33). "Debe también decirse — añade — que nunca actuaba con negligencia y que jamás emprendió una tarea, literaria o de cualquier otro tipo, a la que no dedicase todo el trabajo necesario para llevarla a cabo adecuadamente" (Mill, J.S., Autobiografía, cit., pgs. 33-34). El esfuerzo que hizo James Mill por educar a sus hijos (a John Stuart especialmente) es igualmente digno de admiración: "En mi caso particular —afirma-, ejerció una dedicación, esmero y perseverancia que rara vez, si es que ha habido alguna, ha sido empleada con un propósito semejante: el de impartir, de acuerdo con sus propias ideas, una educación intelectual de la máxima calidad” (Mill, J.S., Autobiografía, cit., pg. 34).

14 "Cuando terminé con el último volumen del Traité - recuerda en su Autobiografía - me había convertido ya en un ser diferente. El 'Principio de la utilidad', entendido tal y como Bentham lo entendía, y aplicado tal y como él lo aplicaba a lo largo de estos tres volúmenes, encajaba perfectamente como piedra angular que unía todos los elementos fragmentarios de mis pensamientos y creencias. Daba unidad a mis ideas de las cosas. Al fin podía yo decir que tenía opiniones, un credo, una doctrina, una filosofía y, en uno de los mejores sentidos de la palabra, hasta una religión cuya propagación y difusión podía constituir el principal y decidido propósito de toda una vida. Tenía ante mí el gran proyecto que, mediante esa doctrina, podía cambiar la condición de la Humanidad" 
todo y con eso, dirigió también, a uno y a otro, críticas acerbas (que probablemente hablen más sus sentimientos propios que de los defectos de sus maestros). Una de las quejas, que reaparece en distintos pasajes de sus obras, tiene que ver con el escaso desarrollo de un mundo emocional.

Por ejemplo, en el artículo dedicado a Bentham, publicado en 1838, Mill, después de alabar el espíritu inquisitivo, sintético y original del filósofo; después de llamarlo maestro de sabiduría; después de destacar su empuje reformador y el valor de su método, pone de manifiesto los defectos que, en su opinión, posee su filosofía. Para empezar, la doctrina de Bentham, dice Mill, no era en absoluto innovadora. ${ }^{15}$ Pero es que además, para continuar, el propio Bentham no fue especialmente brillante y gozaba de algunas cualidades de dudoso valor. ${ }^{16}$ Particularmente, lo más interesante de la crítica de Mill se refiere a la pobreza de Bentham en el terreno de los sentimientos. Según Mill, Bentham despreció en buena medida el mundo de los sentimientos; ni los entendió, ni, en consecuencia, fue capaz de profundizar en su estudio. ${ }^{17}$ Con una miopía emocional de tal calibre, la imagen que pudo tener de la naturaleza humana no podía ser sino deficiente y trunca. El ser humano diseñado por Bentham se mueve por sensaciones de placer y dolor, pero poco más parece capaz de hacer. El mundo emocional, enlazado al desarrollo espiritual y moral, queda disuelto. El deseo de progresar moralmente, la necesidad de perfeccionarse espiritualmente, son aspectos de la existencia humana ajenos a la concepción de Bentham. ${ }^{18}$ En suma,

(Mill, J.S., Autobiografía, cit., pgs. 85-86). Y más adelante concluye: "Las perspectivas de perfeccionamiento que Bentham abría eran suficientemente amplias y brillantes como para iluminar toda mi vida y dar forma definitiva a mis aspiraciones" (Mill, J.S., Autobiografía, cit., pg. 86).

15 "Las generalidades de esta filosofía suya — dice, por ejemplo - tienen poca novedad, si es que tienen alguna" (Mill, John Stuart, Bentham, Madrid, Tecnos, 1993, pg. 26).

16 "Bentham — sostiene Mill— falló a la hora de sacar luz del conocimiento adquirido por otras mentes" (Mill, J.S., Bentham, cit., pg. 34). "Tenía un desprecio inconmensurable hacia algunos de los pensadores más ilustres anteriores a él” (Mill, J.S., Bentham, cit., pg. 35), dice más adelante. "Ciertamente — añade—, por carencia de cultura poética, las imágenes que le proporcionaba su propia facultad imaginativa, pocas veces eran hermosas" (Mill, ibídem). Y, en fin, "lo que él vio en el hombre fue poco más de lo que hasta el ojo más vulgar podía ver" (Mill, J.S., Bentham, cit., pg. 40).

17 Para Mill, Bentham "no tenía simpatía por muchos de los sentimientos más naturales y más fuertes de la naturaleza humana; era totalmente ajeno a muchas de sus experiencias más importantes" (Mill, J.S., Bentham, cit., pg. 38). De este modo, "sabiendo tan poco acerca de los sentimientos humanos, sabía aun menos de las influencias por las que se forman esos sentimientos. Todas las operaciones más sutiles ejercidas por la mente sobre sí misma se le escapaban" (Mill, J.S., Bentham, cit., pgs. 40-41).

18 "El hombre - dice Mill- no es jamás entendido por Bentham como un ser capaz de perseguir, como fin último, la perfección espiritual” (Mill, J.S., Bentham, cit., pg. 46). "El hombre, ese ser tan extraordinariamente complejo — sostiene después-, es para Bentham una realidad muy simple. Incluso en el apartado de la simpatía, la aceptación de este sentimiento no llega a alcanzar sus formas más complejas: el amor a amar" (Mill, J.S., Bentham, cit., pg. 48). 
la teoría que se podía erigir desde esta base, con un ser humano simple y plano, poco podía aportar, ni de original ni de profundo, al desarrollo espiritual (entiéndase también emocional) de la humanidad. En palabras de Mill, una teoría así "no hará nada [...] por los intereses espirituales de la sociedad". ${ }^{19}$

Claro que toda esta crítica no es gratuita; ciertamente lo que más preocupaba a Mill era el hecho de que la implementación de la doctrina utilitarista de Bentham dejaba al margen una parte importante del mundo de los sentimientos humanos. La torpeza de Bentham en este sentido es presentada por su discípulo sin ningún reparo: "El sentimiento de aprobación o desaprobación moral propiamente dichos, ya sea con referencia a nosotros mismos o a nuestros prójimos, es algo de cuya existencia no parece tener noticia", dice en un momento dado. ${ }^{20} \mathrm{Y}$ más adelante: "Confundió todos los sentimientos desinteresados que encontró dentro de sí, con el deseo de felicidad general [...] Se hubiera requerido más sutileza de la que Bentham poseía, para establecer distinciones entre sentimientos que, como resultado de una larga costumbre, actuaban siempre en la misma dirección; y su falta de imaginación no le permitió leer esa distinción allí donde es suficientemente legible: en el corazón de los demás". ${ }^{21}$

Bentham, según Mill, fracasó estrepitosamente al presentar un concepto de moral recortado y limitado y al olvidar por completo otros aspectos importantes más allá de la moralidad. Ambas cuestiones tienen que ver con los sentimientos. Por un lado, desconoció la capacidad de los seres humanos para perfeccionarse moralmente en el ejercicio de sus sentimientos. En palabras de Mill: "La moralidad consta de dos partes. Una de ellas es la autoeducación, el entrenamiento que el mismo ser humano lleva a cabo ejercitándose sobre sus propios afectos y su propia voluntad. En el sistema de Bentham, esa parte está vacía”. ${ }^{22}$ Por otro lado, consideró el aspecto moral como el único capaz de influir sobre los sentimientos de las personas, lo cual tuvo como consecuencia el que se transmitiera una imagen de insensibilidad muy poco atractiva. Lo que ha dado a la filosofía de Bentham "ese aire frío, mecánico y antipático que caracteriza la idea popular que se tiene de un benthamita", dice Mill con cierta amargura, es el error de "tratar la consideración moral de las acciones y de los caracteres como si fuera la única, cuando, en realidad, es sólo una de las tres por las que nuestros sentimientos hacia el ser humano pueden ser, deberían ser y no pueden dejar de ser - a menos que nuestra naturaleza humana quede

19 Mill, J.S., Bentham, cit., pg. 56.

20 Mill, J.S., Bentham, cit., pg. 47.

21 Mill, J.S., Bentham, cit., pg. 49.

22 Mill, J.S., Bentham, cit., pg. 54. 
aniquilada- influidos materialmente". ${ }^{23}$ Para Mill, pues, las acciones humanas pueden y deben ser evaluadas desde su aspecto moral, para llegar a una conclusión sobre su bondad o maldad; pero el ser humano necesita también pronunciarse sobre su aspecto estético, admirar la belleza de la acción o despreciar su torpeza; y necesita considerar su aspecto simpático, que tiene que ver con el sentimiento humanitario que nos permite amar y compadecernos o rechazar a otros. Si, como hace Bentham, prescindimos de los aspectos estético y simpático, cercenamos las fuentes de nuestros sentimientos y, en definitiva, acabamos por desconocer a los seres humanos. Bentham, decía Mill, "escribía y sentía como si la norma moral no es que solamente debiera ser la más importante (que debería), sino la única; como si ella fuera la sola maestra de todas nuestras acciones y hasta de todos nuestros sentimientos; como si admirar o apreciar, despreciar o rechazar a una persona por una acción que no produjese un bien o un daño, o que no produjese un bien o un daño proporcionados al sentimiento albergado, fuese una injusticia y un prejuicio". ${ }^{24}$

La conclusión de Mill creo que puede resumirse en una frase que deja entrever cierta decepción: "No es necesario - dice- extenderse en las deficiencias de un sistema de ética que no pretende ayudar a los individuos en la formación de su propio carácter" ${ }^{25}$

No se puede decir que no fueran ciertas estas consideraciones que Mill expone en 1838 sobre Bentham, pero sí creo que deben ser entendidas en relación con la particular situación emocional de Mill.

$\mathrm{Su}$ padre James conoció a Jeremy Bentham en 1808, cuando John Stuart apenas tenía dos años. A partir de entonces se entabló entre ellos una estrecha relación intelectual y personal. No sólo compartieron ideas y construyeron juntos una doctrina; también disfrutaron de largos periodos en mutua compañía y compartieron la educación de John Stuart. Tal educación consistió, en esencia, en un curso intenso y penetrante de benthamismo. Pero a diferencia de lo que sucedió en el caso de James Mill y de Bentham, cuyo utilitarismo era producto de lo que ellos ya eran, es decir, resultado de sus pensamientos, y, en consecuencia, posterior a su ser Jeremy Bentham y James Mill, en el caso de John Stuart, el utilitarismo no fue algo posterior a su ser John, sino simultáneo; no fue un producto de su manera de ser y de pensar, sino una estructura ajena que lo conformó como persona. Mientras que para James Mill y para Jeremy Bentham el utilitarismo era un algo externo, para John Stuart el utilitarismo era parte

23 Mill, J.S., Bentham, cit., pg. 84.

24 Mill, J.S., Bentham, cit., pg. 86.

25 Mill, J.S., Bentham, cit., pg. 53.

TÉ $\lambda \circ$ 与, Vol. XVII/2, 2010 (145-170) 
de él. Bentham y Mill padre eran ya antes del utilitarismo; Mill hijo no fue sino desde el utilitarismo.

Decía Mill, en este artículo dedicado a Bentham, que éste había confundido todos los sentimientos desinteresados propios con el deseo de felicidad general y que, por ello, fue incapaz de distinguir entre unos sentimientos y otros. Es muy posible que, de alguna manera, John Stuart también fuera víctima de una confusión similar. Habiendo recibido de su padre y de Bentham muchas ideas durante su educación, recibió también las de una doctrina utilitarista $\mathrm{y}$, tal vez, no siendo capaz de distinguir entre unas y otras, creyó que el utilitarismo era un compendio de todas ellas y que el buen utilitarista debía conducirse como Bentham o su padre se conducían en la vida.

Mazlish nos recuerda en su biografía de los Mill que James Mill era un hombre rígido, obsesionado por el trabajo, ansioso y tremendamente controlador de sus sentimientos. Esta represión que ejercía sobre sí era, al decir de Mazlish, lo que le permitió alcanzar un notable éxito público. ${ }^{26}$ Y el mismo John Stuart tenía una imagen de Bentham (real o no, poco importa eso) en la que la el cultivo de los sentimientos apenas se adivina. Afirma, por ejemplo, que Bentham "no tuvo ni experiencia interna ni externa; el tranquilo y monocorde tono de su vida y la buena salud de su mente conspiraron para excluirlo de ambas clases de experiencia. Nunca conoció ni la prosperidad ni la adversidad, ni la pasión ni la saciedad. Ni siquiera tuvo jamás la experiencia que proporciona la enfermedad; desde la infancia hasta la edad de ochenta y cinco años vivió con la salud de un mozo. No conoció ni la depresión ni la melancolía. Nunca sintió la vida como una carga dolorosa y aburrida. Fue un muchacho hasta el fin". ${ }^{27} \mathrm{Y}$, dejando a un lado otras artes, respecto de la poesía, Mill asegura que Bentham "no tuvo la menor predilección. Las palabras, pensaba él, pervertían su función más propia cuando se las empleaba para decir otra cosa que no fuera la estricta verdad lógica". ${ }^{28}$

No es difícil imaginar el tipo de educación que se pueda recibir de dos personas así. La de John Stuart alcanzó niveles de excelencia en muchos aspectos. El rigor y el volumen de conocimientos debió de ser abrumador para un niño. La lista de lecturas adultas que Mill menciona en su autobiografía, es ingente; pero la tristeza se adivina en algunas frases ("de

26 "El éxito político e intelectual de Mill — dice — se debe sin duda en su mayor parte al rígido control de sus emociones en público" (Mazlish, Bruce: James \& John Stuart Mill. Father and Son in the Nineteenth Century, New Brunswick, Transaction Books, 1988, pgs. 65-66).

27 Mill, J.S., Bentham, cit., pg. 40.

28 Mill, J.S., Bentham, cit., pg. 87. 
libros para niños no llegué a leer apenas nada", recuerda);29 y el ambiente que debió de vivir se puede resumir en el recuerdo de un padre que, en sus palabras, "no sólo pedía de mí lo máximo que yo podía hacer, sino también muchas otras cosas que estaban fuera de mi alcance". ${ }^{30}$ En vez de recibir ternura y cariño, su padre le transmitió conocimientos y un rechazo patológico a todo sentimiento. En un momento dado recuerda cómo "se irritaba mi padre ante las alabanzas a favor del sentimiento o ante la menor indicación de que éste tenía influencia a la hora de juzgar a las personas o de discutir cualquier otra cosa". ${ }^{31}$ Para empeorar las cosas, la madre de John Stuart, no supo o no pudo atemperar el carácter de su padre y enseñar a sus hijos a amar. La vivencia de Mill se resume bien en las siguientes palabras: "Una madre realmente cariñosa, en primer lugar, habría hecho de mi padre un ser diferente, y en segundo lugar, habría hecho que sus hijos crecieran amando y siendo amados. Pero mi madre, con sus mejores intenciones sólo supo pasarse la vida luchando penosamente por ellos. Todo lo que podía hacer por ellos lo hizo, y ellos la apreciaban porque era amable; pero hacerse amar, respetar o incluso obedecer, requiere cualidades que ella, por desgracia, no tenía. De este modo, crecí en ausencia de amor y en presencia del temor; y los efectos de esta educación en el estancamiento de mi desarrollo moral fueron muchos e indelebles". ${ }^{32}$

No es necesario añadir más para componer la imagen de una infancia solitaria y llena de tristeza, frustración y rabia contenida. Y también llena de saber científico. Derivado de ello, John Stuart se convirtió en una máquina de razonar y en un ser capaz de vivir al margen de los sentimientos. $\mathrm{Al}$ recordar su adolescencia afirma: "El cultivo de los sentimientos -con excepción del sentido público y privado del deber- no fue cosa muy estimada entre nosotros y ocupó un espacio muy reducido en nuestros pensamientos, particularmente en el mío". ${ }^{33}$

El resultado de este experimento educativo no se hizo esperar. En el otoño de 1826, a los veinte años, John Stuart acabó por derrumbarse anímicamente. "Ni los placeres egoístas ni los generosos eran ya placeres para mí - recuerda en su autobiografía-. Y parecía que la naturaleza no tenía ya poder suficiente para formar de nuevo mi carácter y crear en una mente que ya era irremisiblemente analítica, nuevas asociaciones placenteras con cualquiera de los objetos del deseo humano". ${ }^{34}$ La crisis sentimental de

29 Mill, J.S., Autobiografía, cit., pg. 37.

30 Mill, J.S., Autobiografía, cit., pg. 35.

31 Mill, J.S., Autobiografía, cit., pg. 121.

32 Cit por Packe, Michael St. John, The Life of John Stuart Mill, Londres, Secker and Warburg, 1954, pg. 33.

33 Mill, J.S., Bentham, cit., pg. 122.

34 Mill J.S., Autobiografía, cit., pg. 146. 
Mill era profunda: en una situación así, la posibilidad del suicidio no era descabellada. Packe lo refiere de la siguiente manera: "Desesperadamente intentó cualquier cosa que pudiera hacerle sentir [...] Sólo estaba el espejo de su propio triste dolor, la vacía melancolía de la saciedad [...] No podía sentir, nunca más podría sentir. [...] Decidió concederse un año para desarrollar algún tipo de sentimiento, y después acabar drásticamente con una vida tan agobiante e inútil como era, sin duda, la suya". ${ }^{35}$

La recuperación sentimental de Mill se produce gracias a la lectura de las Memorias de Marmontel, uno de cuyos pasajes le hace emocionarse y tomar conciencia de sus sentimientos. El viraje de Mill a partir de entonces tiene que ver con la recuperación de su parte emocional, lo cual supone también la separación intelectual de su padre y de Bentham. Mazlish asegura que la lectura de este pasaje de Marmontel, en el que el autor enfrenta la muerte de su padre, permite a Mill elaborar en su imaginación una situación similar y resolver su propio conflicto edípico. "La evidencia indica —dice Mazlish (1988: 211)— que al experimentar la muerte imaginaria de su padre y desplazarla al padre de Marmontel, John fue capaz de 'tratar' sus ambivalentes y hasta entonces ocultos sentimientos de amor y odio por su padre. Por un lado, podemos conjeturar que pudo afrontar la posibilidad de la muerte de su padre como la pérdida del objeto amado del que tanto dependía, mediante un periodo de duelo y tristeza. Por otro lado, podemos ver que aceptó sus sentimientos de rivalidad contra su padre matándole de forma sustitutiva y reemplazándole. De esta manera extraña y 'casual' John Stuart Mill pudo afirmar su independencia”. Tal independencia, por cierto, se puede ver manifestada en el descubrimiento de la música y de la poesía (de Wordsworth, principalmente) y en la reelaboración de la doctrina recibida.

Doce años después, en 1838, con su padre muerto hacía dos y Bentham hacía seis, John Stuart es muy capaz de poner de manifiesto los defectos de la doctrina de su maestro. Es fácil tener la impresión de que buena parte de estas críticas va dirigida a su padre. No era, probablemente, el momento de pasar la cuenta a uno y a otro, pero, por otro lado, parece difícil que pudiera haberse olvidado de su tristeza infantil, de su frustración adolescente o del rigor de la autoridad paterna, una de cuyas manifestaciones recientes había estado motivada por la relación de John Stuart con Harriet Taylor, que no era aprobada por James Mill.

No puede decirse que sea falso lo que Mill afirma en su artículo sobre Bentham, pero creo que detrás de ello puede adivinarse su frustración y su rabia contra el mundo sin sentimientos en el que le tocó hacerse y vivir,

Packe, M.St.J., The Life of John Stuart Mill, cit., pg. 78. 
y contra los hombres que lo construyeron. Su acusación de falta de sentimientos apunta a Bentham y a James Mill, pero también a la doctrina que, para John Stuart, recogió está característica.

En mi opinión, lo que dice Mill en su artículo no hace justicia al estudio pormenorizado y complejo que hace Bentham de los sentimientos humanos, aun siendo verdad que la imagen que Bentham proyectó de su sistema fue una imagen científica y, en ese sentido, emocionalmente neutra. El propio Mill parece estar de acuerdo con esta necesidad de dotar de un carácter científico a la doctrina al sostener que "sea o no sea la felicidad el fin último al que debe referirse la moralidad, el que refiramos ésta a una suerte de fin y no la dejemos en los dominios de un sentimiento vago o de una convicción interna inexplicable; el que hagamos de ella cuestión de razón y cálculo, y no meramente de sentimiento, es algo esencial a la idea misma de filosofía moral; es, de hecho, lo que hace posible que haya disputa o discusión acerca de cuestiones morales". ${ }^{36}$

En todo caso, lo que cabe preguntar es si es posible hacer una interpretación diferente del utilitarismo que permita poner en juego los sentimientos y esté, quizá, más en consonancia con el anhelo de Mill.

\section{3. ¿ES POSIBLE UNA INTERPRETACIÓN DE LA DOCTRINA QUE OTORGUE MÁS IM- PORTANCIA A LOS SENTIMIENTOS?}

Decíamos más arriba que buena parte de las críticas que recibe el utilitarismo tiene que ver con el hecho de que la aplicación de la fórmula puede llevar a aceptar conclusiones abominables, como la de pasar por encima de la integridad de las personas o la de violar sus derechos (conclusiones a las que, según se dice, el utilitarista coherente se avendría alegremente). En efecto, si nos atenemos a un riguroso cálculo, parece que en ocasiones tendremos que admitir que sumados los placeres y restados los dolores de todos los afectados, la acción que produce el mejor resultado es la que supone, pongamos por caso, acabar con la vida de una persona. Un utilitarismo apegado a la fórmula, al cálculo y al análisis parece no poder ofrecer nada mejor. ¿Cabe otra interpretación?

Mill aceptaba tanto la importancia del cálculo como herramienta de toda filosofía moral, cuanto reconocía la fuerza disolvente del instrumento del análisis en el ámbito de las emociones, como sostiene, por ejemplo, en su Autobiografía: "Los hábitos analíticos -afirma- pueden incluso fortalecer nuestras asociaciones entre causas y efectos, entre medios y fines, pero tienden a debilitar todas aquéllas otras que, para decirlo en lenguaje

36 Mill J.S., Bentham, cit., pg. 83.

TÉ $\lambda \circ$ 与, Vol. XVII/2, 2010 (145-170) 
común, son mera cuestión de sentimientos". ${ }^{37}$ Tomando esto en cuenta, es decir, considerando, por un lado, la necesidad del cálculo y, por otro, el riesgo del empleo del análisis, quizá se pueda pensar en una interpretación del utilitarismo que no otorgue un papel más importante a las emociones; quizá no sea descabellado pensar en un utilitarismo que no esté tan alejado de los sentimientos.

Mill creía que mediante la educación sería posible inculcar en las personas una conciencia del bien común en el que la felicidad propia y la de todos los seres humanos estuvieran armonizadas, un amor por los demás que pudiera ser "fuente de elevadas emociones y de un principio del deber". ${ }^{38}$ El tipo de persona que parece prefigurar su utilitarismo no es la de un ser calculador e insensible, preocupado por hallar el resultado óptimo de una operación aritmética. Ciertamente, es la imagen que se ha proyectado del benthamita, pero Mill apunta a algo diferente. El utilitarista de Mill parece ser un individuo que ha sabido enlazar su felicidad a la felicidad de los demás, que está preocupado por hacer el bien y que se maneja para ello con una serie de pautas o reglas que le permiten discernir con cierta precisión cuáles son los comportamientos apropiados para ello (reglas, por cierto, que tienen que ver en algunos casos con determinados sentimientos que deben ser protegidos, como cuando sostiene, al tratar de la diferencia entre lo conveniente y lo útil en relación con el deber de decir la verdad: "Puesto que el cultivo en nosotros mismos de un sentimiento delicado en la cuestión de la veracidad es uno de los más útiles, y el debilitamiento de ese sentimiento uno de los más dañinos — dice Mill-, [...] entendemos que la violación, por una ventaja actual, de una regla de conveniencia tan superior, no es conveniente, y el que por consideración a una ventaja para sí o para algún otro, hace todo lo que de él depende para privar a la humanidad del bien, y le causa mal, comprometiendo la mayor o menor confianza que pueden depositar los unos en las palabras de los otros, hace el papel de uno de sus peores enemigos"). ${ }^{39}$

Más allá de este planteamiento reconocible como un utilitarismo de reglas, lo importante es que para Mill una de las cuestiones fundamentales de la moral es la de diseñar los medios para conseguir un desarrollo moral elevado de las personas. Se trata de hacer que las personas se esfuercen en perfeccionarse moralmente para conseguir "un genuino y fuerte deseo de hacer lo que es mejor para la felicidad de todos". ${ }^{40}$

37 Mill, J.S. Autobiografía, cit., pg. 145.

38 Mill, J. S., La utilidad de la religión, Madrid, Alianza Editorial, 1995, pg. 78.

39 Mill, J.S., On Liberty and Other Essays, Oxford, Oxford University Press, 1991, pgs. 154-155.

40 Mill, J.S., "Primeros ensayos sobre el matrimonio y el divorcio", en J.S. Mill y H. Taylor, Ensayos sobre la igualdad sexual, Barcelona, Península, 1973, pg. 91. 
Si esto es así, la función del cálculo empieza a desdibujarse, las reglas aritméticas precisas empiezan a perder fuerza y, en palabras de Mill, "las normas generales se convierten en meras ayudas para la prudencia en la selección de los medios, y dejan de ser obligaciones perentorias" ${ }^{41}$ En suma, el cálculo utilitarista deja de depender de operaciones aritméticas para pasar a basarse en los sentimientos; en concreto, afirma Mill, en "los sentimientos sociales de la humanidad; [en] el deseo de estar en armonía con nuestro prójimo". ${ }^{42}$

Creo que Mill pensaba que conseguir una sociedad así era posible; que según avanzara la civilización, ese sentimiento de afecto con los demás podría ir extendiéndose y propiciando un perfeccionamiento moral continuo de todo el género humano. Así lo confesaba en Utilitarismo al afirmar que "en un estado de perfeccionamiento del espíritu humano, las influencias están creciendo constantemente, lo cual tiende a generar en cada individuo un sentimiento de unidad con el resto; sentimiento que, si es perfecto, hará que no piense ni desee ninguna condición beneficiosa para él en cuyo beneficio no se incluya a los demás". ${ }^{43}$

Una estructura así es semejante a la que pretendía Hume al presentar una moral de la alegría que, decía él, pedía un único esfuerzo: "el de un cálculo justo y una firme preferencia por la mayor felicidad". ${ }^{44}$ Creo que Mill está apuntando a la misma idea y que podemos ver en su utilitarismo más una apelación al sentimiento que una llamada a la aritmética moral. Pienso que esto es coherente con su revuelta contra su padre y contra Bentham, con su crisis emocional y con su planteamiento en relación con las reglas y los derechos y con la persecución de la felicidad general.

Las reglas que Mill postula son más bien reglas prudenciales, basadas en la experiencia de la humanidad, que reglas de cálculo aritmético. "Todas las criaturas racionales — dice Mill- se hacen al mar de la vida con su entendimiento formado en las cuestiones usuales sobre lo correcto y lo incorrecto, tanto como en muchas de las mucho más complejas cuestiones sobre la prudencia y la imprudencia". ${ }^{45}$ Creo que se puede ver claramente esta manera de proceder cuando trata de los derechos. Los derechos a los que él se refiere son algunas de estas reglas que ayudan a discernir lo correcto y lo incorrecto, que nos indican de qué manera se consigue la mayor felicidad. Dice Mill: "Tener un derecho, por tanto, es, entiendo, tener

41 Mill, J.S., ibídem.

42 Mill, J.S., On Liberty and Other Essays, cit., pg. 164.

43 Mill, J.S., On Liberty and Other Essays, cit., pg. 166.

44 Hume, David, Investigación sobre los principios de la moral, Madrid, Alianza Editorial, 1993, pg. 164.

45 Mill, J.S., On Liberty and Other Essays, cit., pg. 157. 
algo en cuya posesión la sociedad debe defenderme. Si el objetante continúa preguntando por qué debe, no puedo darle otra razón que la utilidad general". ${ }^{46}$ En otras palabras, la sociedad debe defenderme protegiendo mis derechos. Y debe hacerlo precisamente porque de esa forma es como se alcanza la felicidad general, de manera tal que los derechos no entran en conflicto con la consecución de la felicidad general, sino que son parte de ella. Por otro lado, estas reglas que son los derechos pueden tener, como todas, determinadas excepciones. Puesto que están pensadas con el fin de promover la felicidad general, la constatación en un caso dado de una disminución grave de la tal felicidad general puede hacer que se deje de lado la regla. $\mathrm{O}$ dicho de otro modo, puesto que lo que se pretende es conseguir la felicidad general, se elaboran determinadas reglas que nos ayudan a decidir y comportarnos (sabemos, diríamos, que siguiendo esas reglas es como se alcanza la felicidad general); pero, a la vez, puesto que lo que pretendemos es conseguir la felicidad general, cuando comprobamos que siguiendo tales reglas lo que se consigue es disminuirla gravemente, el mismo fin nos indica que debemos dejar de lado las tales reglas. Afirma Mill en Utilitarismo, que "si el principio de utilidad vale para algo, debe valer para ponderar estas utilidades opuestas entre sí [la de la regla y la del acto] y trazar el ámbito en el que cada una predomina”. ${ }^{47} \mathrm{Y}$ de eso se trata, en definitiva; de ponderar las utilidades opuestas y de dilucidar, en determinados casos, cómo se consigue la mayor felicidad (siguiendo la regla o dejándola de lado). Adviértase, por otro lado, que el hecho de dejar de lado la regla produce, en sí mismo considerado, una disminución de la felicidad que también debe ser tenida en cuenta.

En todo caso, según lo entiendo, con todo esto no se nos está pidiendo un cálculo preciso, sino una búsqueda sensata, prudente y razonable de la felicidad general. Esto está en consonancia con la imagen del tipo de persona que promueve la doctrina utilitarista, según Mill. Esa es la imagen de alguien que desea estar en armonía con los demás, no como resultado de un deber impuesto, sino como producto de su ser desarrollado moralmente. "Esta creencia - afirma Mill- es la sanción fundamental de la moral de la mayor felicidad. Esto es lo que hace que cualquier espíritu, de sentimientos bien desarrollados, trabaje a favor, y no en contra, de los móviles externos para querer a los demás". ${ }^{48} \mathrm{El}$ utilitarista, diríamos, no es (no debe ser) una persona insensible, que hace cálculos matemáticos acerca de la felicidad. Es, por el contrario, una persona que desea su felicidad y entiende y siente

46 Mill, J.S., On Liberty and Other Essays, cit., pg. 189.

47 Mill, J.S., On Liberty and Other Essays, cit., pg. 155.

48 Mill, J.S., On Liberty and Other Essays, cit., pg. 167. 
que está enlazada a la felicidad de los demás. Es una persona que tiene empatía con los demás y que trabaja por conseguir la mayor felicidad para el mayor número.

Si esto se entiende así, tal vez no sea tan descabellado decir, como dice Mill, que "la felicidad de cada persona es un bien para esa persona, y la felicidad general, por tanto, un bien para el conjunto de todas las personas". ${ }^{49} \mathrm{Si}$ se entiende que la felicidad de cada uno está enlazada a la felicidad general, es decir, si se entiende que uno no puede ser feliz a costa de la infelicidad de los demás, entonces no es tan difícil entender que comprobado que todos desean su propia felicidad (que su propia felicidad es un bien para ellos), queda probado que la felicidad general es un bien para todos. Si mi propia felicidad es un bien para mí y esa felicidad se enlaza a la felicidad general, no queda probado que la felicidad general sea también un bien más allá de mí (pues para los demás puede no serlo); pero si la felicidad de cada uno es un bien para cada uno y eso se enlaza a la felicidad general, parece claro que la felicidad general será un bien para el conjunto (puesto que todos las desean como parte de su propia felicidad).

Y, por cierto, si esto se entiende así, tampoco parece difícil salir al paso de algunas críticas, como las que sostienen que el utilitarismo es impracticable, bien porque no es posible hacer el cálculo de las consecuencias (se trata de un proceso sin fin que nos lleva de consecuencia en consecuencia), o bien porque no es posible comparar la felicidad (es decir, los placeres y los dolores) de las personas. Si nos apartamos del cálculo aritmético, se puede afirmar que no se trata tanto de adscribir puntuaciones a los placeres y dolores de las personas, para situarlos en una escala común, cuanto de ver qué curso de acción es el que permite que más personas sean felices de la manera más armoniosa posible. Lo cual significa que hay consecuencias que se pueden descartar sin que se distorsione el cálculo utilitario, a saber, todas aquellas que no afectan a la armonía del conjunto, y que, en cualquier caso, el cálculo sólo exige el empleo de adverbios comparativos y de cantidad, que permiten que la comparación entre las personas sea posible sin utilizar adjetivos numerales.

En conclusión, lo importante de todo esto es que es posible entender el utilitarismo (en particular el de Mill) no como una llamada al estudio científico y al cálculo aritmético, sino como una llamada al perfeccionamiento moral, a la armonía con los demás y, en definitiva, al desarrollo de los sentimientos que ayudan a conseguir la felicidad general. Bentham tal vez podía pretender que un individuo valorara moralmente una determinada acción sin poner en juego ningún sentimiento. Como decíamos más arriba,

49 Mill, J.S., On Liberty and Other Essays, cit., pg. 169.

TÉ $\lambda \circ$ 与, Vol. XVII/2, 2010 (145-170) 
un buen utilitarista sería capaz de medir dolores y placeres de la misma manera que un buen médico, por ejemplo, sería capaz de medir la cantidad de glucosa en sangre. Y así como el médico no pone en juego sus emociones, en tanto que médico, al hacer el análisis y al comprobar un determinado nivel, así el utilitarista tampoco debe emocionarse al realizar su cálculo. No se quiere decir con ello que no sean capaces de sentir placer o dolor en un momento determinado, producto del resultado encontrado. Pero eso no influirá de ningún modo en la aplicación del cálculo, ni en dicho resultado, ni en la decisión que se deba adoptar producto de lo descubierto. Esa forma de proceder, decíamos, encaja bien con la concepción de persona que tenían Bentham o James Mill; y plasma bien el tipo de personas que eran ellos mismos. La dilucidación moral se circunscribía al cálculo aritmético; el método de evaluación era parte del método científico; y el filósofo moral utilitarista era un científico más. El mundo de los sentimientos es ajeno al mundo moral, puesto que para sumar y restar placeres y dolores no se precisa sentir sino sólo saber (las reglas de la aritmética).

El caso de John Stuart es muy distinto. John Stuart Mill es, desde luego, utilitarista. No podía ser otra cosa que utilitarista, porque creció y se conformó con el utilitarismo. Fue, además, un buen utilitarista, que nunca renunció a serlo (difícilmente hubiera podido). ${ }^{50} \mathrm{En}$ su Utilitarismo se reconoce una doctrina utilitarista clara. La búsqueda de la felicidad, la equiparación de la felicidad y el placer, el enfoque empirista, la importancia del análisis, son elementos que están presentados con rigor y precisión. Se da la circunstancia, además, de que dicha obra es una obra de madurez. Cuando la publica, en 1861, Mill cuenta con cincuenta y cinco años; ni su padre, ni Bentham, muertos hacía muchos años, podían suponer una barrera emocional. Ya no tenía que rendir cuentas a nadie, ni siquiera a su querida Harriet, fallecida también algún tiempo antes. Tampoco se encuentra prisionero de una emoción juvenil ni deslumbrado por el descubrimiento de una teoría novedosa. Lo que escribe, pues, es producto de toda una vida de reflexión, de trabajo, de superación, de perfección. Más allá de posibles imprecisiones menores, Mill dice, básicamente, lo que quiere decir sobre el utilitarismo. Difícilmente se puede sostener, creo, la acusación de falta de consistencia en su exposición. Desde luego, no es Bentham; pero es que tampoco quería serlo. Y no creo que se pueda sostener que Bentham y sólo Bentham representa a la doctrina. El utilitarismo tiene muchas versiones; y la de Mill es una de ellas.

50 Audard, por ejemplo, se refiere a Mill como el "autor del manifiesto de la doctrina" (Audard, Catherine, "Utilitarismo", en Monique Canto-Sperber et al., Diccionario de ética y de filosofía moral, México, Fondo de Cultura Económica, 2001, pg. 1636). 
Por otro lado, como hemos visto, Mill entendía que esa falta de desarrollo en el terreno emocional era un serio obstáculo en la doctrina de su padre y de Bentham, un lastre que les impedía comprender uno de los aspectos fundamentales del comportamiento de los seres humanos. Él mismo sufrió las consecuencias de una vida en la que los sentimientos estaban ausentes o, en el mejor de los casos, marginados y destinados a ocupar un lugar secundario. Nadie, pues, tenía que decirle cuál era la importancia del mundo emocional para el desarrollo general del ser humano y para el progreso moral. En su crítica a Bentham, pone de manifiesto que el ser humano, además de verse afectado e interesado por la cuestión sobre la bondad o maldad de una acción (el aspecto moral), le afecta y le interesa también y en no menor medida el aspecto estético y el aspecto simpático; el ser humano siente la belleza o la torpeza de una acción y siente el amor, la compasión o el rechazo que le producen otros seres humanos al realizar sus acciones. Ambos aspectos enlazan de manera obvia con el mundo emocional; captar la belleza o padecer con otros apunta justamente a una faceta del ser humano que no se puede colmar con operaciones aritméticas. $\mathrm{Y}$ en los reproches dirigidos a su padre, se repite la queja sobre la falta de sentimientos.

Desde luego, Mill no puede dejar de ser utilitarista, y por tanto, no renuncia al cálculo de la felicidad; pero sería raro que una cuestión que aparece repetidamente cuando habla de Bentham y de su padre, las dos figuras que le formaron y le hicieron utilitarista; y que aparece cuando se refiere a su madre; una cuestión que le sume en una profunda crisis que casi le cuesta la vida; la cuestión que conforma y dirige toda su relación con Harriet Taylor; sería raro, decía, que desapareciera de su doctrina moral; sería ciertamente raro que después de destacar la importancia fundamental de los sentimientos para el desarrollo de los seres humanos, eso no tuviera ninguna importancia ni influyera absolutamente en nada en el planteamiento de su utilitarismo. Y bien, si eso es raro, lo que queda es descubrir qué grado de importancia concede Mill a dicha cuestión; qué puesto otorga a los sentimientos en el utilitarismo.

Decíamos antes que como buen utilitarista, que lo es, enlaza el bien moral con la felicidad y con el placer; y como buen utilitarista no desconoce la importancia del cálculo y descarta que un mero sentimiento pueda decidir la cuestión moral: lo bueno o lo malo de una acción no se resuelve en mi sentimiento favorable o desfavorable frente a ella. Cuando dice que la cuestión de la moralidad no se puede dejar librada al sentimiento vago e inexplicable, cuando afirma que es necesario que recurramos al cálculo para que pueda existir un verdadero debate moral, cuando sostiene que no puede ser una cuestión meramente de sentimiento, creo que está dejando la puerta 
abierta para que junto al cálculo aparezcan las emociones. ${ }^{51}$ Que no puede ser meramente una cuestión de sentimiento, significa que el sentimiento exclusivamente no puede ser el instrumento moral (puesto que el cálculo es imprescindible); y eso no significa que haya que excluirlo absolutamente. Si enlazamos esto con la referencia recurrente a los sentimientos cuando habla del utilitarismo benthamita, bien se puede concluir que de alguna manera los sentimientos ocupan un puesto importante en el planteamiento utilitarista de Mill.

A mayor abundamiento, podemos ver que cuando describe a Harriet Taylor, dice de ella que tenía una "intuición moral propia de un carácter de fuertes sentimientos" (Mill, 1986: 186) y que él había llegado a los mismos resultados que ella "mediante el estudio y el razonamiento"; y añade en el mismo párrafo: "lo que yo le debo a ella, incluso en un orden intelectual, es, analizándolo con detalle, casi infinito" (Mill, 1986: 186). Con otras palabras, podemos entender, primero, que la influencia de Harriet Taylor fue muy grande; que lo que ella era, su forma de ver el mundo, sus puntos de vista, modificaron en gran medida, a ojos del propio afectado, las ideas de Mill; segundo, que esa influencia tuvo que ver, además, con la cuestión moral (no sólo, pero también); tercero, que esa influencia apunta a una manera de analizar las cuestiones morales en la que ocupan un lugar primordial los sentimientos; y cuarto, que las conclusiones a las que llegaba su mujer con este método eran las mismas que las alcanzadas con el suyo.

Con todos estos materiales, creo que se puede llegar a la conclusión de que Mill presta una atención a los sentimientos que no puede desconocerse. Bien es cierto que no abandona el cálculo, pero, de alguna forma, lo hace compatible con las emociones. De una manera aparecen al tratar de otras facetas del ser humano. Los seres humanos, y el buen utilitarista entre ellos, no son, pues, seres calculador o máquinas de razonar. Son seres que tienen y deben tener un mundo de sentimientos rico y profundo. Y si esa es la imagen del ser humano, no podemos decir que la moral tiene que apuntar a un ser que muy poco tiene que ver con éste. La moral tiene que ver con un ser humano completo, no con uno trunco. Lo bueno y lo malo moral encajan en una estructura mucho más compleja, en la que los sentimientos no se pueden dejar a un lado. Y siendo esto así, el cálculo moral

51 Véase Mill J.S., Bentham, cit., pg. 83. En su Autobiografía sostiene: "La noción de que las verdades externas a la mente pueden conocerse mediante intuiciones o introspecciones mentales, independientemente de la observación y la experiencia, es [...] el gran apoyo intelectual que reciben las falsas doctrinas y las perniciosas instituciones de nuestros tiempos. Con la ayuda de esta teoría, toda creencia inveterada y todo sentimiento intenso cuyos orígenes nadie puede recordar, se libran de la obligación de justificarse racionalmente y se erigen como completa garantía y justificación de sí mismos" (Mill, J.S., Autobiografía, cit., pg. 216). 
no puede dirigirse sólo a la promoción de un ser humano que sólo tome en cuenta placeres y dolores al estilo de Bentham; sencillamente, porque el ser humano no es así. Así pues, para empezar la cuestión del placer o dolor producido por una acción es sólo una parte de la valoración de esa acción y de la valoración del ser humano que la ejecuta. Y como parte que es de un todo, no puede aparecer como la única ni puede aparecer separada de las demás. Y si no puede aparecer separada de las demás es porque la entendemos de algún modo enlazada con ellas. Dicho en otras palabras, es verdad que el cálculo moral tiene que ver directamente con la felicidad, con el placer y con el dolor, pero no puede desentenderse totalmente de esos otros sentimientos que forman parte del aspecto estético o del aspecto simpático. Todos los aspectos conforman al ser humano completo y, en consecuencia, lo bueno moral está en armonía con las demás partes. La moral, podemos decir, se enriquece con la belleza, con el amor, con la compasión. $\mathrm{Y}$ el progreso del ser humano, su perfeccionamiento, no puede realizarse sino en conjunto.

El ser humano que diseña Mill es un ser humano consciente de que su felicidad está enlazada a la felicidad de los demás; un ser humano que desea vivir en armonía con otros; que desea alcanzar la mayor felicidad del mayor número; que sabe que para alcanzar un resultado que sea mayor que otra cosa es necesario medir y calcular de algún modo; pero que sabe también que ese vivir en armonía con otros, ese alcanzar la felicidad mayor del mayor número tiene que ver con alcanzar una forma de ser que va más allá del hecho frío de que la suma de sus placeres supere a la de sus dolores; una forma de ser que apunta, sobre todo, al goce de los placeres superiores y al deseo de perfeccionamiento moral. Y esto no es tanto cálculo aritmético cuanto goce interior. Nadie que quiera disfrutar de una puesta de sol dedica mucho tiempo a calcular dónde, exactamente, debe situarse para tener la mejor vista, aunque quizás haya un lugar que sea mejor que el resto. Lo único que es necesario tomar en consideración es que uno quiere disfrutar de la puesta de sol, que sabe cuáles son las condiciones aproximadas para llegar a ello, y que no le preocupa descubrir el mejor lugar sino justamente eso que pretende, disfrutar de una puesta de sol. Obviamente, hay lugares desde los que es imposible hacerlo, pero dejando esos a un lado, basta con elegir un lugar desde el que, según todas las apariencias, se puede llegar al objetivo que se pretende. Ningún buen cocinero, que yo sepa, calcula los granos de sal que necesita el plato que prepara. Quizás haya un número perfecto de granos necesarios, pero, sinceramente, a nadie le interesa. Porque lo que interesa es el resultado final; y para llegar a él no es necesario ese cálculo. Desde luego, es necesario algún cálculo, pues si no fuera así la cantidad de sal sería algo azaroso; pero el cálculo se subordina 
al resultado que se busca, y en esa medida se desdibuja. Ya no queda expresado en miligramos, sino en adjetivos tales como mucho, poco o bastante.

Y bien, ¿por qué en otros ámbitos de la vida iba a ser diferente? Dice Mill en Utilitarismo que "los pensamientos de la persona más virtuosa no necesitan ir, en estas ocasiones, más allá de las concretas personas interesadas, excepto lo que sea necesario para asegurarse de que beneficiándoles a ellos no está violando los derechos - esto es, las expectativas justas y autorizadas- de nadie más". ${ }^{52}$ Creo que puede ser una buena muestra de cómo pretendía que nos manejáramos en el ámbito moral. Si tenemos en cuenta el resultado que queremos, esa vida armoniosa en unión con otros, esa vida en la que podamos alcanzar la felicidad, la mayor felicidad del mayor número, entonces nuestro cálculo moral debe difuminarse en favor de ese objetivo. Buscamos una forma de vida determinada, un tipo de vida en la que los sentimientos que la hacen atractiva y merecedora de elogio se entreveran para dar un producto armonioso; y para alcanzarlo nos basta con saber qué hacer de manera aproximada, dejando a un lado los comportamientos más toscos y acercándonos a nuestro objetivo con ayuda de las reglas que han ido formándose con la experiencia de la vida en común. He ahí el cálculo moral. Y porque nos interesa ese objetivo, nuestro cálculo no puede hacerse de otra manera. Quien se entretenga considerando todos los lugares posibles y haciendo comparaciones y mediciones, perderá la puesta de sol que deseaba ver; quien se entretenga contando los granos de sal que necesita el plato que prepara, nunca lo terminará. Quizá la medición exacta sea necesaria para otros ámbitos, pero, desde luego no lo es para el disfrute de la vida. Y así, quien se entretenga calculando placeres y dolores y haciendo mediciones precisas, no conseguirá nunca su objetivo: alcanzar la máxima felicidad para el mayor número. Dicho con otras palabras, no importan los granos de sal que se empleen porque nuestro sentido del gusto no puede apreciar una variación con tal precisión. Con toda seguridad, un grano más hará la comida más salada, pero nosotros somos incapaces de percibir tal cosa. Percibimos, diríamos, en grueso, a grandes rasgos, de manera aproximada. Por eso un aparato que midiera los granos de sal sería de todo punto inútil. Porque no somos así, porque no percibimos así. Únase a eso el hecho de que el número de granos de sal que se necesitan para alcanzar el gusto pretendido es relativo al resto de los ingredientes. Lo que se busca es un todo armónico, y la sal es uno de los ingredientes del todo. Manejamos, en definitiva, la sal, en función de nuestra forma de saborear. Trasladémonos al ámbito de la felicidad para constatar lo mismo. $\mathrm{Al}$ fin y al cabo, también cuando hablamos de la felicidad precisamos de 
un enlace con las sensaciones que nos transmiten nuestro sentidos. Sentimos de acuerdo con ellas y sentimos, también, en general, de esa manera aproximada. Muchas pequeñas modificaciones de las sensaciones son imperceptibles. Y de esta manera, la medición tiene un límite, pasado el cual se vuelve ridícula, absurda e inútil. Medimos la felicidad en función de cómo percibimos y sentimos, lo mismo que medimos el buen gusto de un plato porque los instrumentos con los que contamos son los mismos, los únicos que tenemos; porque sólo somos nosotros mismos percibiendo y sintiendo, ya sea el gusto de una comida o la felicidad en términos más generales.

Hay, pues, un cálculo, pero se trata de un cálculo en el que no se emplean adjetivos numerales, sino adverbios comparativos y de cantidad. Esta forma de conducirse es consecuencia de haber enriquecido la imagen de los seres humanos con el mundo de los sentimientos. El objetivo de la moral es alcanzar ese tipo de existencia; y, por otro lado, la medición que hacemos se impregna también de ella, es decir, que calculamos, en este sentido, en tanto sentimos. Calculamos haciendo una comparación entre el criterio de medición (la felicidad) y el objeto que queremos medir (un determinado comportamiento, por ejemplo); y en esta comparación no está ausente el sentimiento, pues forma parte del criterio y no puede no formar parte de la medición. En esto consiste, según creo, el desviacionismo de Mill; en conceder un puesto principal a los sentimientos en la vida humana.

\section{Bibliografía}

AUDARD, Catherine: "Utilitarismo", en Monique Canto-Sperber et al., Diccionario de ética y de filosofía moral, México, Fondo de Cultura Económica, 2001.

AYER, Alfred: Ensayos filosóficos, Barcelona, Planeta-Agostini, 1986.

BENTHAM, Jeremy: A Fragment on Government and An Introduction to the Principles of Morals and Legislation, Oxford, Basil Blackwell, 1960. BENTHAM, Jeremy: Escritos económicos, México, Fondo de Cultura Económica, 1965.

DAMÁSIO, António: O erro de Descartes. Emoção, razão e cérebro humano, Mem Martins, Publicações Europa-América, 2005.

DWORKIN, Ronald: Los derechos en serio, Barcelona, Ariel, 1977.

FERRATER MORA, José: Diccionario de filosofía, 5 vols., Barcelona, RBA, 2005.

HUME, David: Investigación sobre los principios de la moral, Madrid, Alianza Editorial, 1993.

MACKIE, J. L.: Ética. La invención de lo bueno y lo malo, Barcelona, Gedisa, 2000. 
MAZLISH, Bruce: James \& John Stuart Mill. Father and Son in the Nineteenth Century, New Brunswick, Transaction Books, 1988.

MILL, John Stuart: Autobiografía, Madrid, Alianza Editorial, 1986.

MILL, John Stuart: On Liberty and Other Essays, Oxford, Oxford University Press, 1991.

MILL, John Stuart: Bentham, Madrid, Tecnos, 1993.

MILL, John Stuart: La utilidad de la religión, Madrid, Alianza Editorial, 1995.

MILL, John Stuart y TAYLOR, Harriet: "Primeros ensayos sobre el matrimonio y el divorcio”, en J.S. Mill y H. Taylor, Ensayos sobre la igualdad sexual, Barcelona, Península, 1973, pgs. 87-112.

MOORE, George Edward: Ética, Barcelona, Labor, 1989.

NINO, C. S.: Ética y derechos humanos, Barcelona, Ariel, 1989.

NOZICK, Robert: Anarquía, Estado y utopía, Buenos Aires, Fondo de Cultura Económica, 1991.

PACKE, Michael St. John: The Life of John Stuart Mill, Londres, Secker and Warburg, 1954.

RAPHAEL, David Daichies: Filosofía moral, México, Fondo de Cultura Económica, 1986.

RAWLS, John: Teoría de la justicia, Fondo de Cultura Económica, Madrid, 1995.

SMART, J. J. C. y WILLIAMS, Bernard: Utilitarianism: For and Against, Cambridge, Cambridge University Press, 1988.

\author{
Íñigo Álvarez Gálvez \\ Universidad de Chile \\ e-mail: ialvagal@hotmail.com
}

